\title{
Low-Level Middle East \\ Respiratory Syndrome Coronavirus among Camel Handlers, Kenya, 2019
}

Peninah M. Munyua, Isaac Ngere, Elizabeth Hunsperger, Adano Kochi, Patrick Amoth, Lydia Mwasi, Suxiang Tong, Athman Mwatondo, Natalie Thornburg, Marc-Alain Widdowson, ${ }^{1,2}$ M. Kariuki Njenga ${ }^{1}$

Although seroprevalence of Middle East respiratory coronavirus syndrome is high among camels in Africa, researchers have not detected zoonotic transmission in Kenya. We followed a cohort of 262 camel handlers in Kenya during April 2018-March 2020. We report PCRconfirmed Middle East respiratory coronavirus syndrome in 3 asymptomatic handlers.

Since the first human case of Middle East respiraStory syndrome coronavirus (MERS-CoV) was identified in 2012, the World Health Organization has reported 2,494 infections and 858 deaths (case-fatality ratio $34.4 \%$ ) in persons across 27 countries in the Middle East, Europe, Asia, and North America (1). Dromedary camels (Camelus dromedarius) are the known reservoirs of the virus $(2,3)$. Most human cases result from direct or indirect transmission of virus from camels or human-to-human transmission in healthcare settings; researchers have also documented limited secondary transmission to household contacts (4). Occupational direct contact with camels is a risk factor for primary MERS-CoV infection (5). Camel workers and herders have a $0 \%-50 \%$ seroprevalence of MERS-CoV, generally higher than that of the general population in Saudi Arabia $(4,6)$.

Although infection is widespread among dromedary camels, zoonotic transmission from camels to humans is sporadic, and disease prevalence among

Author affiliations: US Centers for Disease Control and Prevention, Nairobi, Kenya (P.M. Munyua, E. Hunsperger, M.A. Widdowson); University of Nairobi, Nairobi (I. Ngere); Washington State University, Nairobi (I. Ngere, M.K. Njenga); County Government of Marsabit, Marsabit, Kenya (A. Kochi); Kenya Ministry of Health, Nairobi (P. Amoth, A. Mwatondo); Kenya Medical Research Institute, Nairobi (L. Mwasi); US Centers for Disease Control and Prevention, Atlanta, Georgia, USA (S. Tong, N. Thornburg)

DOI: https://doi.org/10.3201/eid2704.204458 humans is not directly proportional to potential exposure to infected camels $(4,5,7)$. Although $>65 \%$ of the world's dromedary camels live in Africa, on that continent MERS-CoV seroprevalence in humans is low $(0.2 \%)$, with no documented cases of acute human infection $(8,9)$. Furthermore, studies in the Africa region have identified MERS-CoV RNA in $11 \%-16 \%$ of camels and in $80 \%-95 \%$ of seropositive camels (9-11). To determine whether MERS-CoV infections occur in humans in a region with high seroprevalence among camels, we studied a cohort of 262 camel handlers in Kenya.

\section{The Study}

During April 2018-March 2020, we enrolled participants on a rolling basis from 32 camel-owning households in Marsabit County, northern Kenya (Figure $1)$. We defined a camel handler as any person in the household who had contact with camels (Figure 2). This study was approved by the Scientific and Ethical Review Committee of Kenya Medical Research Institute (approval no. SSC3472), the Institutional Review Board of Washington State University (approval no. 16245), and the US Centers for Disease Control and Prevention (approval no. 7065). We obtained written informed consent from all participants.

We conducted monthly visits with the participants. At each visit, we collected nasopharyngeal and oropharyngeal swab samples from each participant. We also administered a questionnaire to each participating camel handler to identify signs and symptoms of possible respiratory illness during the previous 30 days. In addition, we recorded occurrences of respiratory illness among their household members. Participants belonged to 32 households with a median of 6

\footnotetext{
${ }^{1}$ These senior authors contributed equally to this article. ${ }^{2}$ Current affiliation: Institute of Tropical Medicine, Antwerp, Belgium.
} 


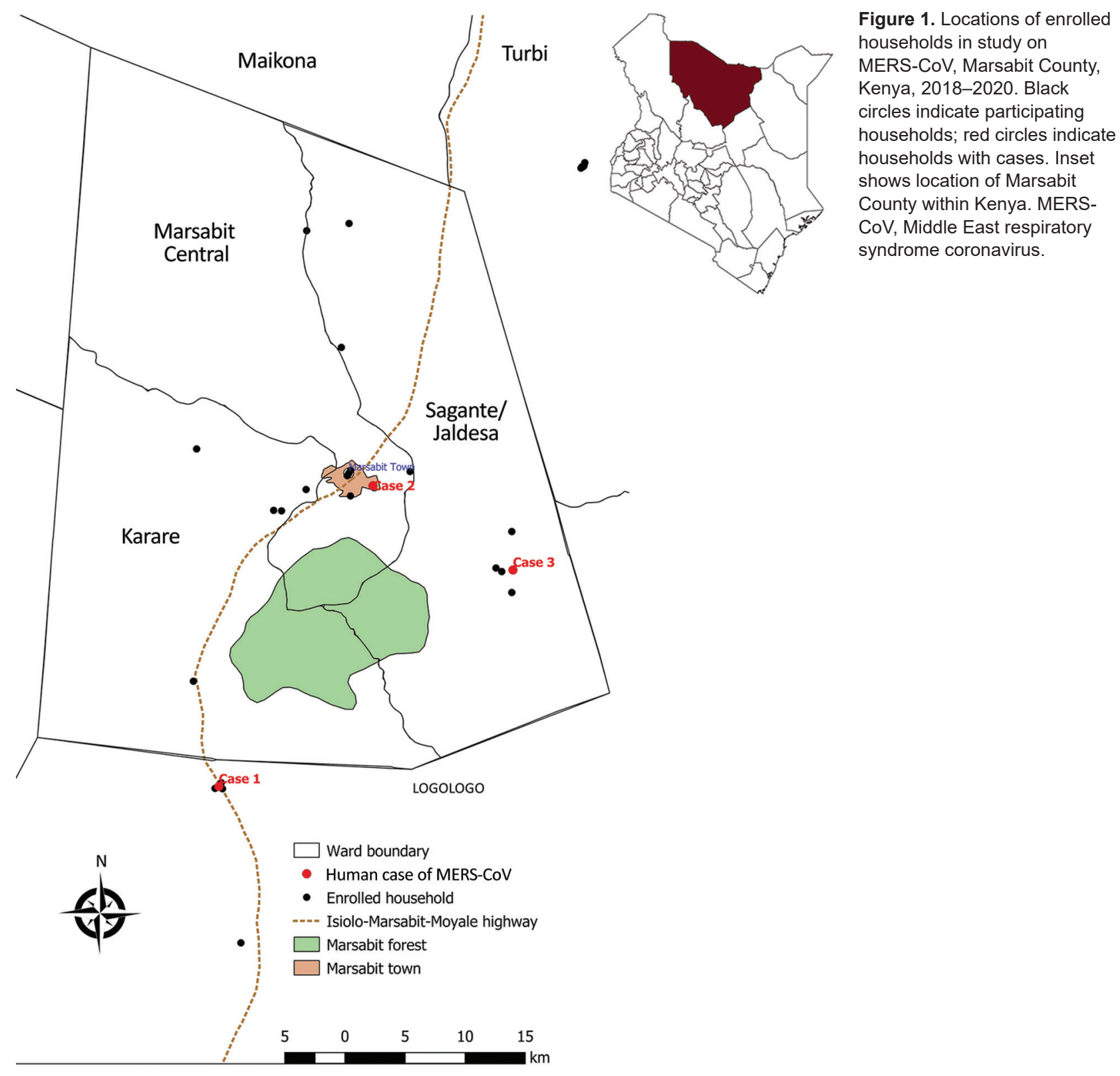

Figure 1. Locations of enrolled in study on Kenya, 2018-2020. Black circles indicate participating households; red circles indicate households with cases. Inset shows location of Marsabit County within Kenya. MERSCoV, Middle East respiratory syndrome coronavirus.

persons (interquartile range [IQR] 1-8 persons) and 32 camels (IQR 2-48 camels) at enrollment. The median age of these participants was 19 years (IQR 11-38 years). Most (67.2\%) participants were male, of whom $39.3 \%$ were employed as camel workers and $38.2 \%$ were school going household members (Table 1). All participants handled camels. The most frequent interactions were herding (74.4\%), cleaning barns (67.9\%), feeding (67.6\%), and milking (63.7\%) (Figure 2).

We stored the swab samples in virus transport media and tested them for MERS-CoV by reverse transcription PCR (RT-PCR) at the Kenya Medical Research Institute (Nairobi, Kenya) as described previously (12). We conducted real-time RT-PCR selec- tive for the upstream region envelope and 2 distinct regions of nucleocapsid genes on total nucleic acid extracted from $200 \mu \mathrm{L}$ of sample. We defined a positive sample by positivity of all 3 PCRs.

We tested 1,369 samples from 262 camel handlers during the 2-year follow-up period. Participants had a median of $43.6 \%$ of monthly follow-up visits (IQR $8 \%-75 \%)$. Three $(1.1 \%)$ participants (cases $1-3)$ tested positive for MERS-CoV by RT-PCR. The cycle threshold $\left(C_{t}\right)$ values for case 1 were 38.9 for the upstream envelope, 37.7 for the nucleocapsid 2, and 39.3 for the nucleocapsid 3 genes; for case 2, the values were 39.7 for the upstream envelope, 36.9 for the nucleocapsid 2, and 39.8 for the nucleocapsid 3 genes; for case 3, 


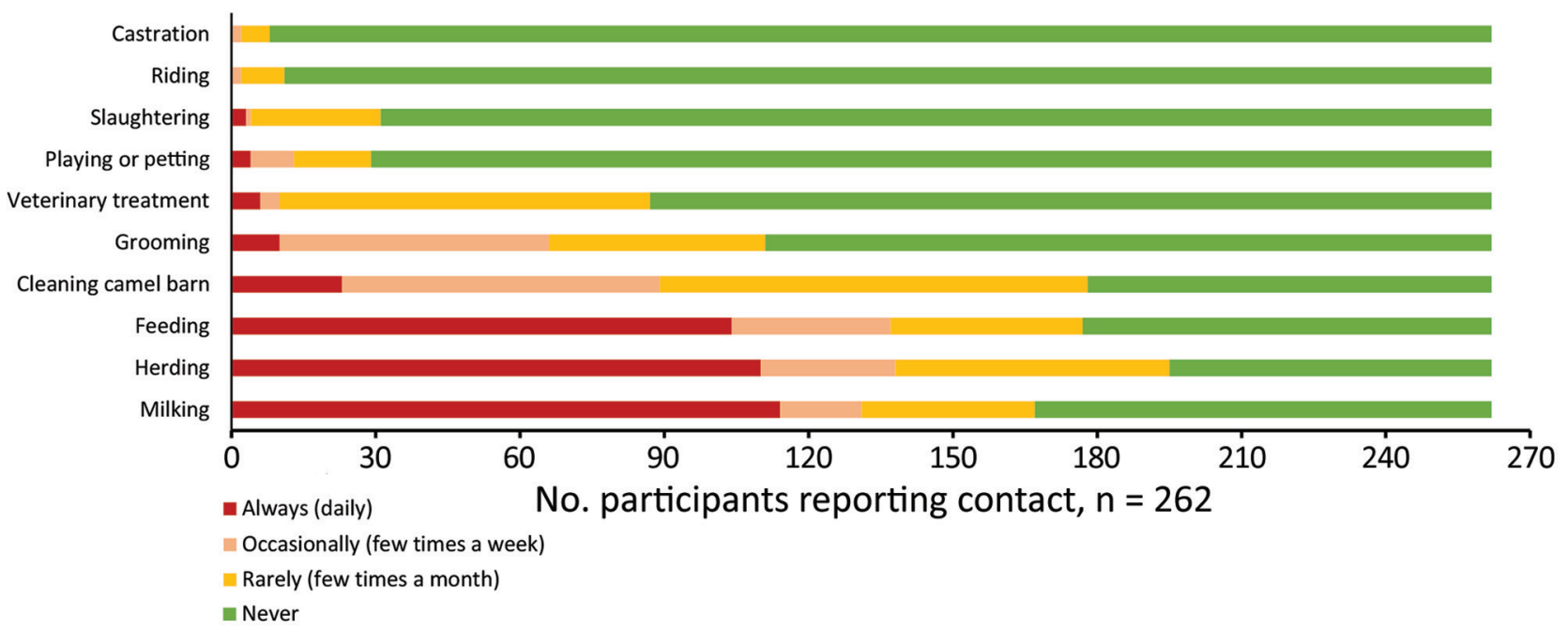

Figure 2. Types and frequency of contacts with camels among participants in study on Middle East respiratory syndrome coronavirus, Marsabit County, Kenya, 2018-2020.

the values were 35.6 for the upstream envelope, 36.0 for the nucleocapsid 2, and 36.8 for the nucleocapsid 3

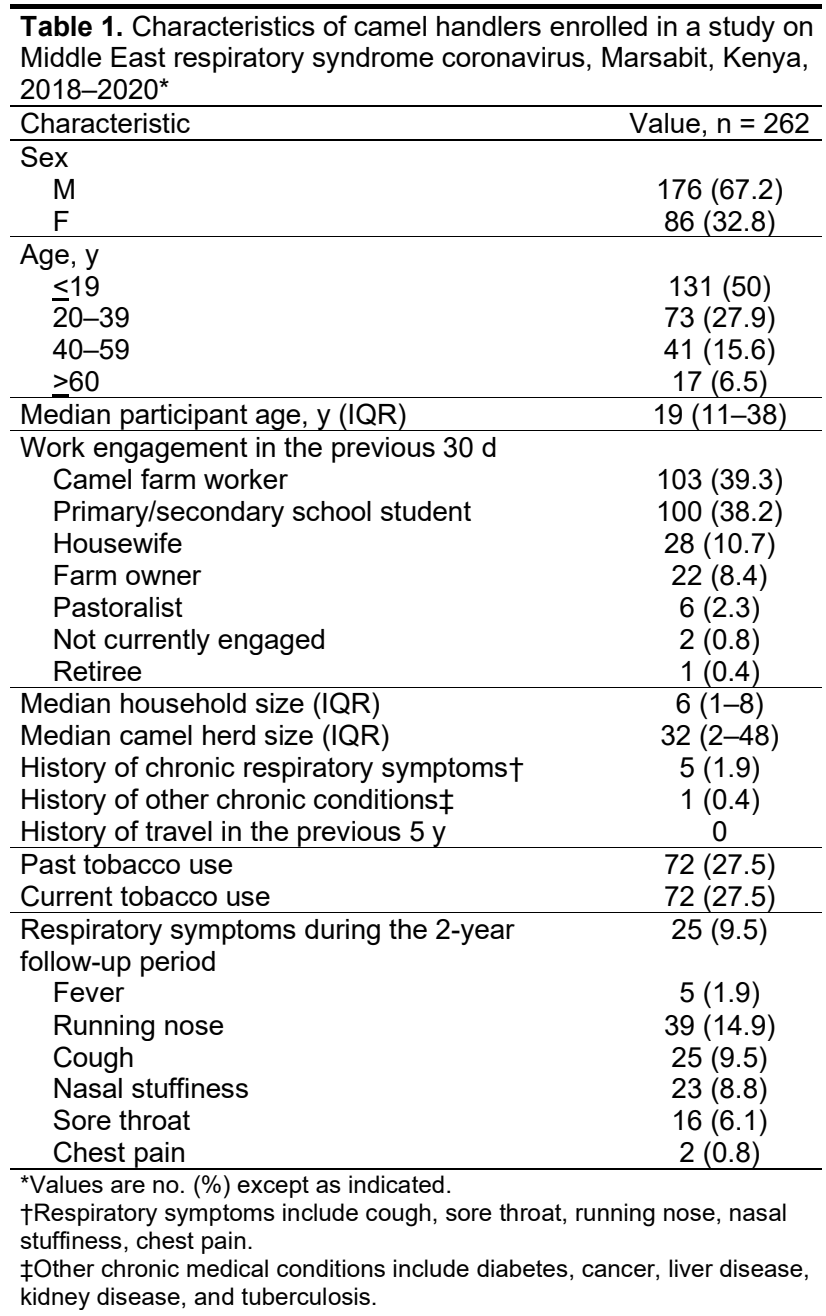

genes. We detected all 3 cases during July-September 2019 (Table 2).

Case 1 was in a woman 20 years of age who enrolled in June 2019 and had 9 monthly follow-up visits. She participated in the study with 11 other members of the household, all of whom tested negative for MERS-CoV throughout the follow-up period. Case 2 was in a man 49 years of age who enrolled in May 2019 and had 7 monthly follow-up visits. He participated in the study with 6 of his 10 household members; all the participants in his household tested negative for MERS-CoV. Case 3 was in a man 22 years of age who enrolled in May 2018 and had 12 monthly follow-up visits. He participated in the study with 3 of his 9 household members; the participants in his household tested negative for MERS-CoV. None of the 3 with positive results tested positive for MERS$\mathrm{CoV}$ in the subsequent months.

All of the 3 with positive results were asymptomatic at diagnosis and had no concurrent conditions or history of travel outside of the county or country in the previous month. None of them or their household members had respiratory illness before or after diagnosis.

\section{Conclusions}

We report 3 PCR-confirmed cases of MERS-CoV in humans in Kenya; these cases met the World Health Organization case definition of MERS-CoV infection (13). All 3 persons were asymptomatic before and after diagnosis; this finding supports previous data suggesting that the virus causes no or mild disease in Africa compared with the Middle East and Asia, perhaps because of the younger age of most camel herders in Africa $(4,8,9)$. Our findings are limited by the high $C_{t}$ values $(>35)$ of all 
Table 2. Characteristics of persons with Middle East respiratory syndrome coronavirus, Kenya, 2019

\begin{tabular}{lccccccc}
\hline Case & $\begin{array}{c}\text { Age, } \\
\text { y/sex }\end{array}$ & Occupation & $\begin{array}{c}\text { No. household } \\
\text { members in } \\
\text { study }\end{array}$ & $\begin{array}{c}\text { No. of camels } \\
\text { owned by } \\
\text { household }\end{array}$ & $\begin{array}{c}\text { Enrollment } \\
\text { date }\end{array}$ & $\begin{array}{c}\text { Diagnosis } \\
\text { date }\end{array}$ & $\begin{array}{c}\text { Type of camel contact at time } \\
\text { of positive sample }\end{array}$ \\
\hline 1 & $20 / F$ & $\begin{array}{c}\text { Spouse to } \\
\text { herder }\end{array}$ & 11 & 37 & 2019 Jun 23 & 2019 Jul 31 & $\begin{array}{c}\text { Herding, milking, feeding, } \\
\text { petting/playing, grooming, } \\
\text { cleaning barn }\end{array}$ \\
2 & 49/M & Herder & 6 & 2 & 2019 May 21 & 2019 Aug 13 $\begin{array}{c}\text { Herding, milking, feeding, } \\
\text { grooming, cleaning barn, } \\
\text { administering medications } \\
\text { Herding, milking, feeding, } \\
\text { grooming, cleaning barn, } \\
\text { assisting in birth }\end{array}$ \\
\hline
\end{tabular}

cases, a level which some experts might not consider to be positive. However, because these cases had $C_{t}$ values $<40$ for 3 distinct MERS-CoV genes, we feel confident that these are unlikely to be false positive results. Researchers have observed low upper respiratory tract RNA concentrations in asymptomatic patients and contacts of MERS-CoV patients (14). In contrast to studies conducted in the Middle East, we found no evidence of human-to-human transmission; a total of 20 household members of the 3 patients tested negative for MERS$\mathrm{CoV}$ before and after their household member's diagnosis. However, we might have missed some infections that occurred between follow-up visits. Furthermore, not all household members were enrolled in the study. In addition, serologic assessment of MERS-CoV T-cell responses might detect mild and asymptomatic MERS$\mathrm{CoV}$ cases (15). Finally, the low (0.2\%) seroprevalence among participants who had high exposure to camel herds with MERS-CoV circulation suggest a low level of zoonotic camel-to-human transmission. We previously found no antibodies against MERS-CoV in camel herders despite high seroprevalence among camels in this community (9).

In conclusion, we confirmed zoonotic transmission of MERS-CoV from camels to handlers in Kenya. Focused surveillance is needed to detect these rare infections when they occur.

\section{Acknowledgments}

We thank Arithi Mutembei, Jack Omolo, Diba Denge, Boru Dub Wato, Millicent Minayo, Moshe Alando, Doris Marwanga, and Cynthia Awuor for their contribution to data and specimen collection. We appreciate the camel herders in Marsabit who participated in this study. We also thank the administrative team at the Washington State University Global Health Program for facilitating all study logistics.

This project was funded by the US Centers for Disease Control and Prevention under the research co-operative agreement with Washington State University (grant no. 1U01GH002143).

\section{About the Author}

Dr. Munyua is an epidemiologist within the Division of Global Health Protection, Global Health, US Centers for Disease Control and Prevention, Nairobi. Her research interests include infectious and zoonotic diseases.

\section{References}

1. World Health Organization. Middle East respiratory syndrome coronavirus (MERS-CoV) summary updates, November 2019. 2019 [cited 2020 Jul 6]. https:/ / www.who. int/emergencies/mers-cov/en

2. Ali MA, Shehata MM, Gomaa MR, Kandeil A, El-Shesheny R, Kayed AS, et al. Systematic, active surveillance for Middle East respiratory syndrome coronavirus in camels in Egypt. Emerg Microbes Infect. 2017;6:1. https:/ / doi.org/10.1038/ emi.2016.130

3. Reusken CB, Farag EA, Jonges M, Godeke GJ, El-Sayed AM, Pas SD, et al. Middle East respiratory syndrome coronavirus (MERS-CoV) RNA and neutralising antibodies in milk collected according to local customs from dromedary camels, Qatar, April 2014. Euro Surveill. 2014;19:20829. https://doi.org/10.2807/1560-7917.ES2014.19.23.20829

4. Grant R, Malik MR, Elkholy A, Van Kerkhove MD. A review of asymptomatic and subclinical Middle East respiratory syndrome coronavirus infections. Epidemiol Rev. 2019;41:6981. https:// doi.org/10.1093/epirev/mxz009

5. Hui DS, Azhar EI, Kim YJ, Memish ZA, Oh MD, Zumla A. Middle East respiratory syndrome coronavirus: risk factors and determinants of primary, household, and nosocomial transmission. Lancet Infect Dis. 2018;18:e217-27. https:/ / doi.org/10.1016/S1473-3099(18)30127-0

6. Alshukairi AN, Zheng J, Zhao J, Nehdi A, Baharoon SA, Layqah L, et al. High prevalence of MERS-CoV infection in camel workers in Saudi Arabia. MBio. 2018;9:e01985-18. https://doi.org/10.1128/mBio.01985-18

7. Hemida MG, Al-Naeem A, Perera RA, Chin AW, Poon LL, Peiris M. Lack of Middle East respiratory syndrome coronavirus transmission from infected camels. Emerg Infect Dis. 2015;21:699-701. https:// doi.org/10.3201/ eid2104.141949

8. Liljander A, Meyer B, Jores J, Müller MA, Lattwein E, Njeru I, et al. MERS-CoV antibodies in humans, Africa, 20132014. Emerg Infect Dis. 2016;22:1086-9. https:/ / doi.org/ 10.3201/eid2206.160064

9. Munyua P, Corman VM, Bitek A, Osoro E, Meyer B, Müller MA, et al. No serologic evidence of Middle East respiratory syndrome coronavirus infection among camel farmers exposed to highly seropositive camel herds: a household linked study, Kenya, 2013. Am J Trop Med Hyg. 2017;96:1318-24. https:// doi.org/10.4269/ajtmh.16-0880 
10. Chu DKW, Hui KPY, Perera RAPM, Miguel E, Niemeyer $\mathrm{D}$, Zhao J, et al. MERS coronaviruses from camels in Africa exhibit region-dependent genetic diversity. Proc Natl Acad Sci U S A. 2018;115:3144-9. https:/ / doi.org/10.1073/ pnas. 1718769115

11. Corman VM, Jores J, Meyer B, Younan M, Liljander A, Said MY, et al. Antibodies against MERS coronavirus in dromedary camels, Kenya, 1992-2013. Emerg Infect Dis. 2014;20:1319-22. https://doi.org/10.3201/eid2008.140596

12. Corman VM, Ölschläger S, Wendtner CM, Drexler JF, Hess M, Drosten C. Performance and clinical validation of the RealStar MERS-CoV Kit for detection of Middle East respiratory syndrome coronavirus RNA. J Clin Virol. 2014;60:168-71. https:// doi.org/10.1016/j.jcv.2014.03.012

13. World Health Organization. Middle East respiratory syndrome case definition for reporting to WHO. 2017 [cited 2020 Oct 2]. https://www.who.int/csr/disease/ coronavirus_infections/mers-interim-case-definition.pdf

14. Drosten C, Meyer B, Müller MA, Corman VM,

Al-Masri M, Hossain R, et al. Transmission of MERScoronavirus in household contacts. N Engl J Med.

2014;371:828-35. https:/ / doi.org/10.1056/NEJMoa1405858

15. Mok CKP, Zhu A, Zhao J, Lau EHY, Wang J, Chen Z, et al.

T-cell responses to MERS coronavirus infection in people with occupational exposure to dromedary camels in Nigeria: an observational cohort study. Lancet Infect Dis. 2020;S1473 3099(20)30599-5. https:/ / doi.org/10.1016/ S1473-3099(20)30599-5

Address for correspondence: Peninah Munyua, US Centers for Disease Control and Prevention, PO Box 606, Nairobi 00621, Kenya; email: ikg2@cdc.gov

\section{Emerging Infectious Diseases Spotight Topics}
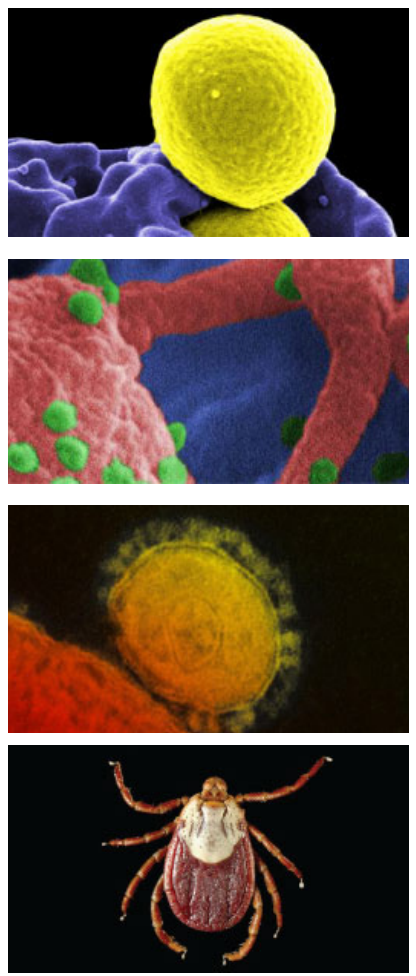
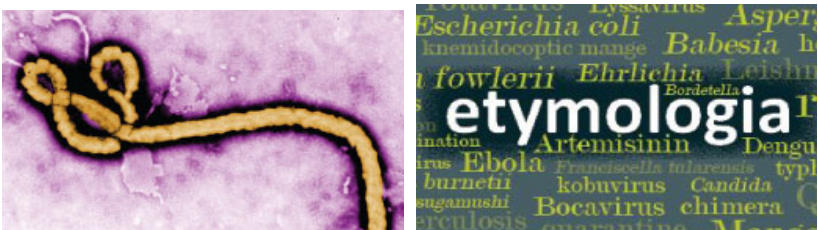

Antimicrobial resistance • Ebola Etymologia Food safety • HIV-AIDS Influenza • Lyme disease • Malaria MERS • Pneumonia • Rabies • Ticks Tuberculosis • Coronaviru • Zika
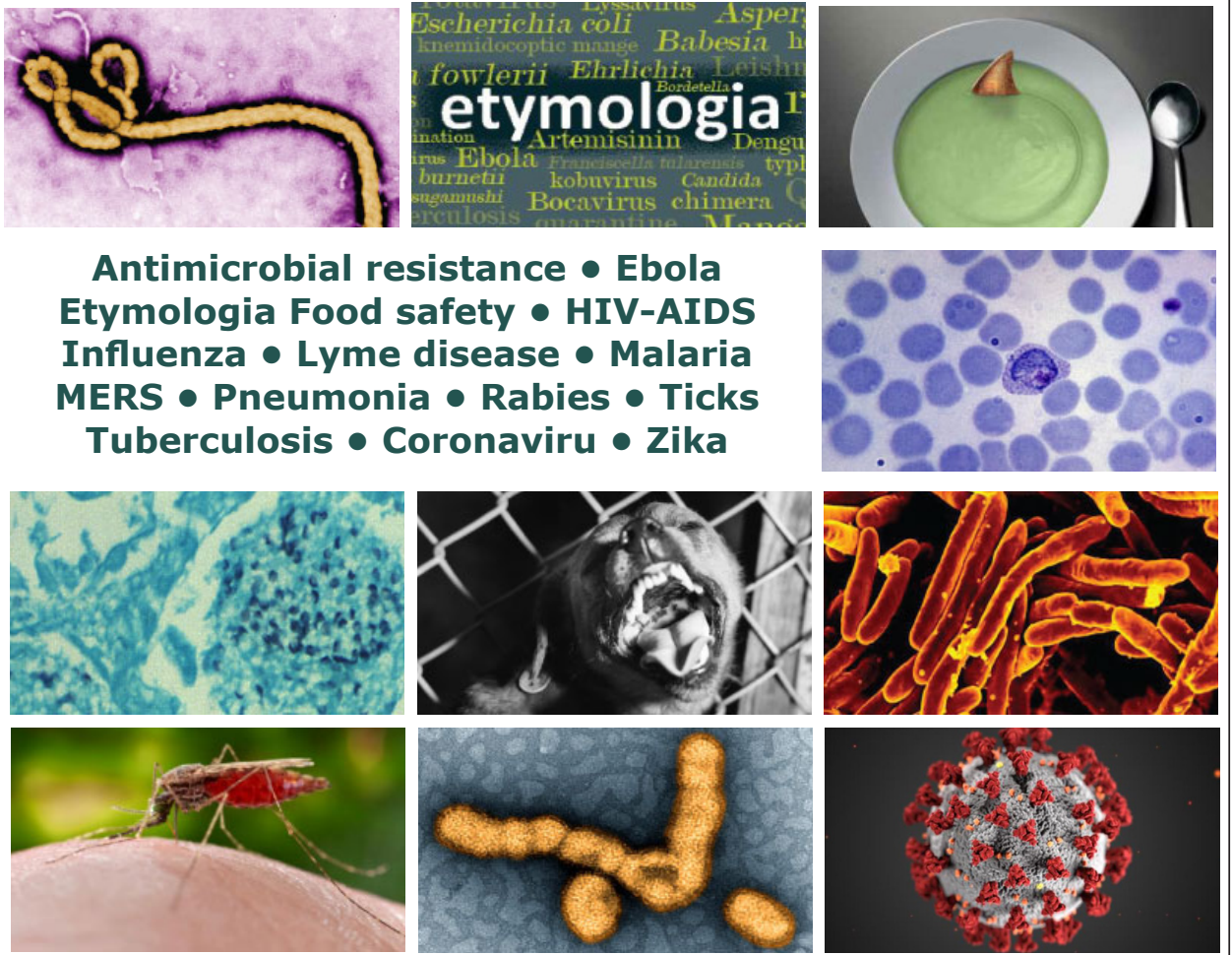

EID's spotlight topics highlight the latest articles and information on emerging infectious disease topics in our global community https:/ / wwwnc.cdc.gov/eid/page/spotlight-topics 